\title{
Research on Operation Analysis and Evaluation Method of Ergonomics for Virtual Assembly
}

\author{
Guobin Gou ${ }^{1}$, Xu Zhang ${ }^{1}$ and Yuehui Yan ${ }^{2}$ \\ ${ }^{1}$ School of Mechanical Engineering Beijing Institute of Technology. Beijing 100081, China \\ ${ }^{2}$ China Academy of Launch Vehicle Technology. Beijing 100076, China
}

\begin{abstract}
With the rapid development of digital technology and virtual reality technology, virtual reality technology has been paid more and more attention by more and more people. To investigate the application of virtual assembly simulation and improve ergonomics, the study on the interactive assembly operation has been performed. A Comprehensive Evaluation Method for ergonomics based on simulation of virtual assembly operations is proposed, aiming at avoid inadequate working postures, effectively improve assembly quality and shorten the production cycle. In this paper, the virtual assembly technology is introduced to the assembly process of an industrial manipulator. Details of the virtual assembly simulation process of an industrial manipulator design and its implementation are presented. This proposed method provides great support to the design of assembly process and brings about good change in the ergonomics of machine and system visualization. The analysis of this instance plays a guiding role in the optimization of human factors engineering.
\end{abstract}

Keywords: virtual assembly, assembly operation, ergonomics, evaluation.

\section{Introduction}

To succeed and gain the competitive advantage in today's fiercely competitive global market, companies must launch new products with higher quality in a shorter time. Meanwhile, the workload of assembly tasks is getting heavier and heavier with the production cycle becoming shorter and shorter, which puts forward higher demand for the workers. Assembly process is the last cycle of product to the market, the assembly quality will directly affect the brand image of the company. Manual assembly is still the most viable method for assembly task. The quality of a product largely depends on the experience of worker. The efficiency and healthy of workers may be affected because of the unreasonable assembly scheme or working in the uncomfortable condition for a long time, which will likely lead to error operations, low efficiency. One of the most popular methods to effectively grapple with that problem in advance is to carry out virtual assembly simulation 1. However, the application of virtual assembly is basically limited to process control and physical simulation stage, research on the simulation of interactive virtual assembly operations has been few studied to date.

In recent years, virtual assembly technology has enjoyed an explosive growth. From the beginning to now, it has been a model of industrial design in the manufacturing industry and has gradually been applied in aerospace products, ships, automobile manufacturing and other fields 2. Therefore, the article is to discuss the application of DELMIA software in the simulation of assembly operations and the improvement of the operating environment and study the assembly process planning with digital people involved, where worker operation should be taken into consideration to provide a more practical reference for assembly process design. By the construction of an ergonomic evaluation method for simulation of virtual assembly operation, a comprehensive analysis can carried out including physical workload, psychological load, posture comfort, etc. to make the analysis and evaluation of virtual assembly easier for users, which plays great roles in application and practice in improving the overall design level of products, the man-machine adaptation capability of equipment and shortening the development cycle.

People raise more and more concern about ever the technology of assembly evaluation in quality which involves in Man, Machine, Material, Method and Environment. In terms of life cycle of product, must give priority to the simplification of structure by the assembly of the parts and its processing characteristics, so the assembly quality evaluation is focused on the assemblability evaluation of the product.

In terms of the analysis of virtual assembly ergonomics, George Chryssolouris et al. made a research on the relationship of the layout of operation and its intensity to ensure good operations on the basis of the lifting equation of NOISH (The National Institute for 
Occupational Safety and Health) and the energy expended model of Gragg 3. With regards to the judgement of fatigue status of digital humans through operational force analysis, Allen et al. 4 quantitatively evaluated the operation force and posture of manual assembly by virtual assembly technology and at the same time, they also implemented the research of the maximum assembly force and the average assembly force for each assembly cycle in order to avoid the repeat labor. On the evaluation of working postures, Mohamad et al. 5 completed the task by CATIA software to evaluate the postures of packaging industry workers, and they found that heavy objects and bending in operations have bad effect on the comfort of operation, which could be checked and improved by RULA gesture assessment.

\section{Research on operation analysis of virtual assembly}

This section gives priority to analyse the characteristics of the virtual assembly in environment and common human issues and discusses the application of DELMIA software in the simulation of virtual assembly and the improvement of the operating environment. First of all, in order to simulate the assembly, the entire assembly simulation can be completed through the building of virtual assembly environment by DELMIA software to build the virtual operation. Then, a simulation study is performed on the typical operations to discover and improve the irregular operation in the process in advance.

\subsection{Simulation platform}

The digital lean manufacturing application DELMIA (Digital Enterprise Lean Manufacturing Interactive Application) introduced by Dassault Systemes in France is characterized by strong simulation. As a subsystem for simulation of manufacturing and maintenance (PLM), DELMIA is able to perform simulation analysis of the entire manufacturing and maintenance in important equipment fields such as aerospace and defense, shipbuilding and automotive. The platform of the digital process planning, DPE has the capability of establishing product data, resource data and process structure to evaluate process plans and output results of assembly process. DPM is able to verify the simulation through the process flow of DPE and assembly process simulation. The digital human model is aimed to analyze the product design and ergonomic project. Ergonomic avatars are created as soon as possible with the DELMIA/Human module.

\subsection{The decomposition for virtual assembly}

Typical assembly operations are simulated with the DELMIA software to build a virtual assembly task. Based on the actual assembly task and motion analysis theory, the assembly operation hierarchy structure diagram is established, and the assembly operation is decomposed into assembly operation activity layer to form a series of basic assembly action units to realize the action simulation of the assembly task.

Operation Analysis (OA) is focused on analysis including objectives and methods of operations, work environment that affect the its efficiency and quality. According to different research objects, operation analysis is classified into four categories, as shown in Figure 1. The simulation in the report refers to that of the operation process in accordance with the assembly task, including the hands handling material, hand tightening fasteners and the lifting operation of components by the equipment 6.As for the virtual assembly, it should be studied by virtual ergonomic workers, virtual assembly tools, products to be assembled and lifting mechanisms to analyze the relationship among the operators, operations and work environment to improve the efficiency of assembly operations.

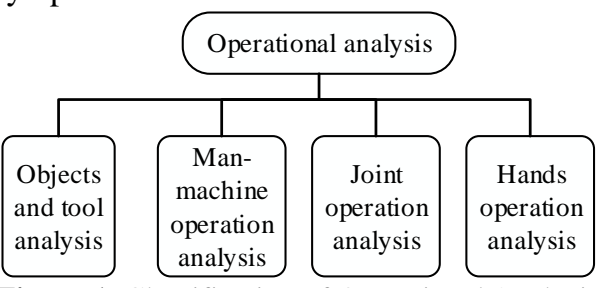

Figure 1. Classification of Operational Analysis

The hands operation analysis is mainly to avoid hand operation to improve work efficiency. Man-machine operation analysis is designed to make full use of energy balance of tools and personnel.

\subsection{Motion analysis}

Motion Analysis (MA) mainly studies body movements in the course of operation to eliminates unnecessary movements so as to formulate an optimal operation sequence and standard operation method 7. The American scholar Gilbuss discovered that the artificial operation consists of 18 motive factors and put forward the method of factor analysis that decomposes operation actions into basic action elements. Based on the theory of concentric circles proposed by Professor Zhou Dao and the impact of various factors on operations, these motive factors can be divided into inactive motives unrelated to operations, supporting therblig and effective therblig in the promotion of work 8 .

1) Effective motives in the promotion of work is made up of common therblig and core ones with 8 categories. As seen in the Table 1.

Table 1. List of common therblig and core therblig

\begin{tabular}{|c|c|l|}
\hline Category & Name & \multicolumn{1}{|c|}{ Instructions } \\
\hline \multirow{4}{*}{$\begin{array}{c}\text { Common } \\
\text { therblig }\end{array}$} & Stretch out & Leaving or closing the objectives \\
\cline { 2 - 3 } & Hold & $\begin{array}{l}\text { Holding objectives in arms or } \\
\text { figures }\end{array}$ \\
\cline { 2 - 3 } & Move & Changing the direction of objectives \\
\cline { 2 - 3 } & Loosen & Loosing thins \\
\cline { 2 - 3 } $\begin{array}{c}\text { Core } \\
\text { therblig }\end{array}$ & Preposition & Preposition before being fixed \\
\cline { 2 - 3 } & Assembly & Combining two objectives \\
\cline { 2 - 3 } & Use & $\begin{array}{l}\text { Changing objectives by tools or } \\
\text { device }\end{array}$ \\
\cline { 2 - 3 } & Disassemble & Disassembling combined objects \\
\hline
\end{tabular}


2) Supporting therblig: it is obtained by effective therblig without direct relationship with operation. As an auxiliary factor, it should be cancelled or shortened as much as possible. The motion consists of 6 elements, as shown in Table 2.

Table 2. List of supporting therblig

\begin{tabular}{|c|c|l|}
\hline Category & Name & \multicolumn{1}{|c|}{ Instructions } \\
\hline \multirow{4}{*}{$\begin{array}{c}\text { Supporting } \\
\text { therblig }\end{array}$} & Examine & $\begin{array}{l}\text { Comparing the product to standard } \\
\text { one }\end{array}$ \\
\cline { 2 - 4 } & Look for & $\begin{array}{l}\text { Searching the location of the } \\
\text { objective }\end{array}$ \\
\cline { 2 - 3 } & Choose & Choosing the movements \\
\cline { 2 - 4 } & Plan & Considering the next action \\
\cline { 2 - 4 } & Position & Being in right place \\
\cline { 2 - 3 } & Find & $\begin{array}{l}\text { The movements founded by } \\
\text { objective }\end{array}$ \\
\hline
\end{tabular}

3) Invalid therblig: It has nothing to do with the operation, a delaying element, and must try to cancel them, which is focused by us, as seen in Table 3.

Table 3. The list of invalid therblig

\begin{tabular}{|c|c|c|}
\hline Category & Name & Instructions \\
\hline \multirow{3}{*}{$\begin{array}{c}\text { Invalid } \\
\text { therblig }\end{array}$} & Holding & Keeping objective static \\
\cline { 2 - 3 } & Stop & Stopping only \\
\cline { 2 - 3 } & Delay & Caused by objective factors \\
\cline { 2 - 3 } & Avoidable Delay & Caused by subjective factors \\
\hline
\end{tabular}

\subsection{Analysis of actions in key processes}

The therblig reflects the movement characteristics of the assembler and the assembly operation can be decomposed into basic therblig, which constitutes the most basic operation movement unit of the assembly. Because of different shapes, sizes and weights, the description of the process is also different, but according to the real function, it can be roughly divided into feeding, positioning, assembly, connection, marking, inspection and discharge. assembly simulation should be facilitated on the basis of different combinations of therblig. The basic assembly operation is mainly related to that of the product without the adjustment of the posture in the course of assembly. The simulation of digital assembly is in separate with the simulation of adjustment of the posture according to the needs of the operation. On the basis of the therblig classification method of ergonomics and the requirements of the virtual assembly simulation for therblig, this paper takes the posture adjustment and position adjustment into consideration as basic therblig elements, composing the basic therblig of virtual assembly. The classification and definition of therblig are shown in Table 4.

Table 4. Basic therblig of virtual assembly

\begin{tabular}{|c|c|l|}
\hline Category & Name & \multicolumn{1}{c|}{ Instructions } \\
\hline \multirow{4}{*}{$\begin{array}{c}\text { Basic } \\
\text { therblig } \\
\text { of virtual } \\
\text { assembly }\end{array}$} & Move & Changing direction \\
\cline { 2 - 3 } & Carry & $\begin{array}{l}\text { Catching the objective } \\
\text { carried by people }\end{array}$ \\
\cline { 2 - 3 } & Position & $\begin{array}{l}\text { The alignment of tools and point, line } \\
\text { and surface of the objective }\end{array}$ \\
\cline { 2 - 3 } & Place & $\begin{array}{l}\text { Place objective in the location of } \\
\text { assembly }\end{array}$ \\
\cline { 2 - 3 } & Examine & Examining whether the installation is \\
\hline
\end{tabular}

\begin{tabular}{|c|c|l|}
\hline \multirow{2}{*}{ Pose } & $\begin{array}{l}\text { appropriate } \\
\text { Adjusting until the posture is } \\
\text { appropriate }\end{array}$ \\
\cline { 2 - 3 } Assembly & \begin{tabular}{l} 
Installing subjective in right way \\
\hline Hold
\end{tabular} $\begin{array}{l}\text { Without change in posture and } \\
\text { direction }\end{array}$ \\
\hline Tool & Installing by tools \\
\hline Release & $\begin{array}{l}\text { Releasing tools or subjective after } \\
\text { operation }\end{array}$ \\
\hline
\end{tabular}

At present, the analysis of the assembly process is only focused on assembly operations without therblig that better shows the characteristics of operators. For example, in the procedure of robot assembly, the fastening of the guide rails by screw, the assembly operation unit includes walking to the work station, grabbing the fastening tool, sending it to the assembly hole, aligning the top tight, tightening the screws, changing the working posture and placing wrenches 9 . This paper proposes to decompose the assembly, which will reflect the characteristics of the operator in movement. The specific operation is shown in Figure 2.

The assembly event refers to one or more operations, such as electrical wiring and inspection and commissioning due to a fault or scheduled plan. The assembly operation is a part of it, including the installation of components of the robot, the disassemble and installation of the connector and the like 10. The basic assembly belongs to a work unit of decomposition of the assembly. For example, the assembly movement system can be decomposed into guide rail installation, tightening screws, mounting gaskets, the installation of mechanical stopper and limit switches and horizontal plates installation. The therblig of assembly means specific action of the assembler to complete the assembly. For instance, the fastening of the guide rails by screw, the assembly operation unit includes walking to the work station, grabbing the fastening tool, sending it to the assembly hole, aligning the top tight, tightening the screws, changing the working posture and placing wrenches 11 .

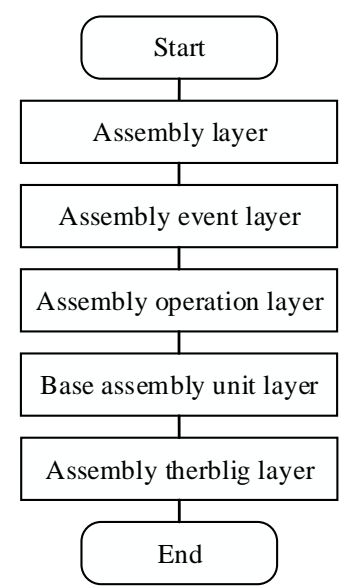

Figure 2. The hierarchy chart of assembly operation

\section{Study on work efficiency evaluation method for virtual assembly}

The section puts forwards to a comprehensive evaluation model based on multi-fuzzy comprehensive evaluation 
and analysis method of hierarchy, which provides a solution to the problem of work comfort evaluation for virtual assembly. The relevant theoretical methods and analysis of modeling process are described below in detail.

\subsection{Ergonomics analysis and evaluation index system of assembly}

Based on the simulation of the assembly operation, the comprehensive evaluation of the ergonomic analysis of the operator is designed to establish a corresponding index system. The selection of indicators is the basis for its establishment. Therefore, the selection of indicators is required for further research. First, a framework for evaluation indicators built by analyzing the ergonomic design standards and similar index system of ergonomic evaluation of assembly operations. In terms of the qualitative and quantitative requirements for assembly operations and the characteristics of the work environment of simulation assembly, preliminary evaluation indicators were selected and an index system suitable for ergonomic analysis of virtual assembly operations were established 12.

According to the characteristics of virtual assembly operations and the general steps of comprehensive evaluation, the process of establishing a comprehensive evaluation method of load-comfortability based on virtual assembly is summarized that consists of three parts. It's evaluation index, evaluation implementation methods and evaluation criteria. Based on the requirements for assembly, the selection of evaluation factors should be based on the feasibility of the integrated evaluation method applied in the simulation environment so that they are able to complete the analysis by instruments of simulation platform of the virtual assembly. The evaluation criteria are the core of the framework; the evaluation criteria in each evaluation index will have great effect on the accuracy of the evaluation. The main reference for the evaluation criteria refers to the description of requirements of the assembly operation based on the selected indicators 13 . The specific chart of the evaluation of the comfort of virtual assembly operations is shown in Figure 3.

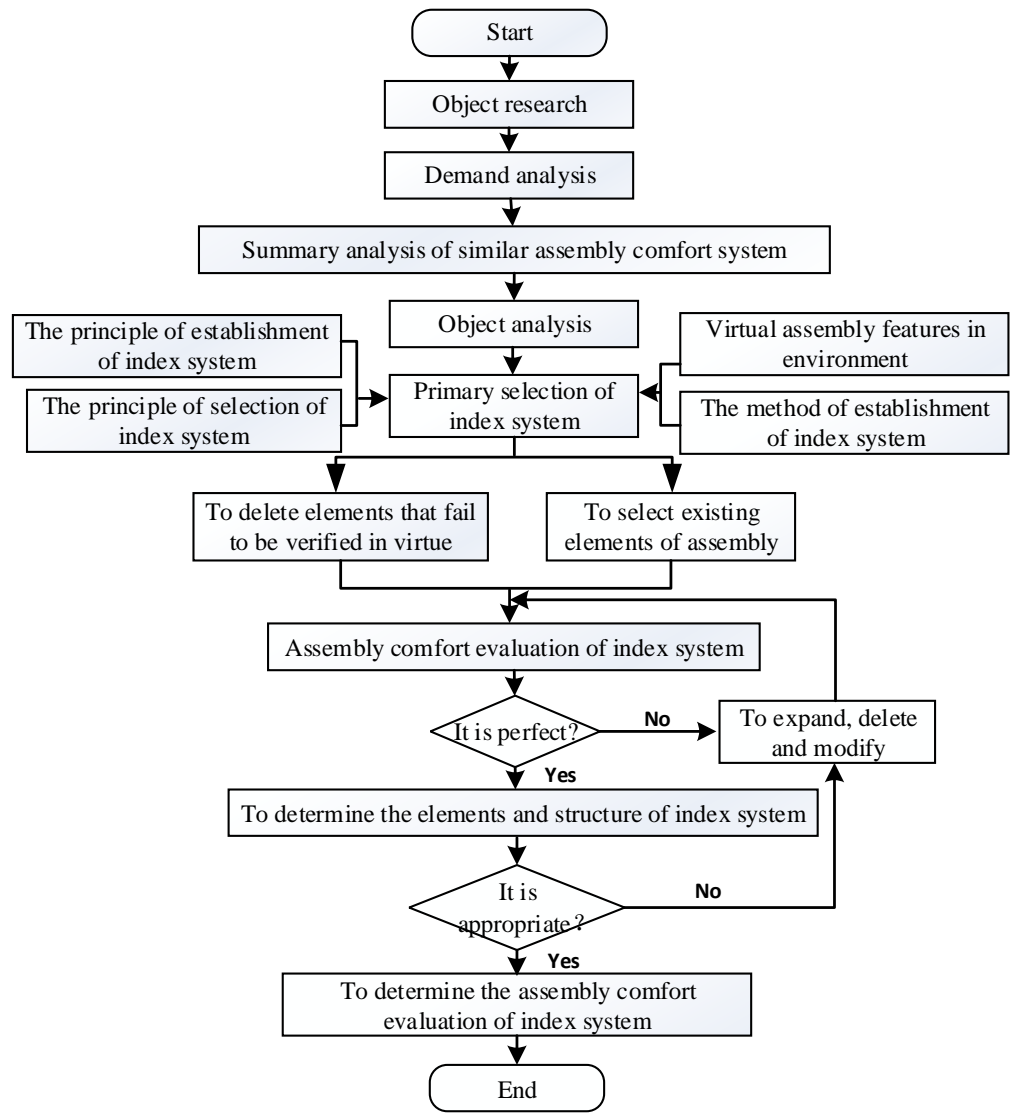

Figure 3. Flowchart for the construction of a comprehensive evaluation index system for the comfort of assembly operations

As shown in Figure 3, the analysis achieved by the characteristics of work environment of the virtual assembly and actual needs. Taking the existing research on the ergonomic evaluation index of assembly operations as a reference, a framework of evaluation indicators is initially constructed; with focus on the relevant requirements of the assembly operation, the evaluation index system initially screened out through the combination of the previous requirements analysis and the characteristics of the virtual assembly environment.
Based on the preliminary indicator system, the index system can be expanded, deleted or modified by analyzing and judging whether the evaluation index system is perfect and whether the index can be verified under virtual conditions; the previous basic evaluation index system is classified, analyzed and gathered to establish the elements of assembly comfort evaluation index, among which each one is made up of a number of basic indicators. Each element and its supporting indicators are part of ergonomic evaluation index system 
of the assembly. It is necessary point out that since the evaluation index elements are inseparable from basic indicators, the latter is re-extended, deleted and modified when the evaluation index elements are incomplete, unreasonable in its structure or insufficient in its support. Then, the framework is re-established by a new basic index system.

The influences on operation comfort include improper posture, work intensity and duration, environment, psychological load, degree of match between tools and equipment and people 15. This article defines the comfort of the load: in the course of the assembly operation, the operator can succeed in completing the task within the specified time without discomfort, where he bears load including psychological, physical strength, posture and the environment. On the basis of the characteristics of virtual assembly operations in environment, the following evaluation indicators are selected: work posture, strength, noise, work content, work time and labor mode (carrying, picking, pushing and pulling).

Comprehensive analysis is carried out in the ergonomic requirements of assembly operations in a virtual assembly and a comprehensive evaluation index system for work comfort of virtual assembly to describe that the operator can succeed in completing the task within the specified time without discomfort, where he bears load including psychological, physical strength, posture and noise.

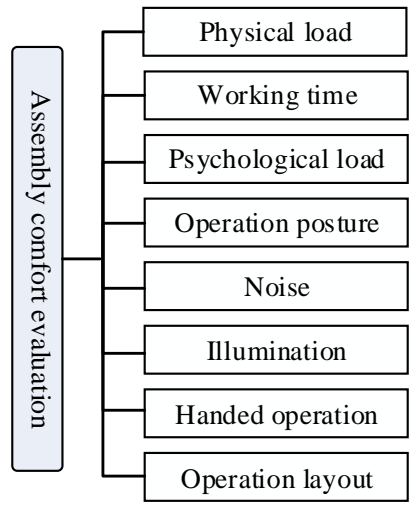

Figure 4. Comprehensive evaluation index system of comfort of load of assembly

\subsection{Fuzzy comprehensive evaluation}

Comprehensive evaluation refers to the evaluation of the complex system with multiple indicators which will integrate the indicator system, establish a comprehensive evaluation model and makes use of the model to evaluate and sort the objects 16 . The choice of evaluation methods has a great influence on the its correctness. Different problems will have different evaluation method. When it comes to multi-objective evaluation, the evaluator should give priority to understand and analyze the evaluation object, the expected effect and the conditions. Then evaluation methods are screened out to ensure its effectiveness and objectivity according to the characteristics of the problem and the requirements for the evaluation.
Fuzzy Comprehension Evaluation (FCE) is based on the theory of fuzzy mathematics membership, in which it quantitatively transforms fuzzy indicators by construction of hierarchical fuzzy subsets and implements comprehensive evaluation on membership of multiple indices 17.The fuzzy comprehensive evaluation consists of six basic components: domain $\mathrm{U}$, a kind of judging factor, set $\mathrm{V}$ related to the judging grade, matrix $\mathrm{R}$, a fuzzy relation, matrix $\mathrm{W}$, a kind of judging factor, the composition operator and vector $S$ relevant to the evaluation result. Its basic principle: first, to determine the domain of the set $U=\left(u_{1}, u_{2}, \ldots, u_{n}\right)$ and the set of domain of comment level $\mathrm{V}=\left(v_{1}, v_{2}, \ldots, v_{m}\right)$ for each indicator, among which $u_{i}$ refers to individual evaluation index and $v_{j}$ to its level of judgement. Then the weight of $\mathrm{W}$ and membership vector $\mathrm{R}$ for each indicator is determined. After fuzzy transformation, the matrix R of the fuzzy relation can be obtained. Finally, the matrix $\mathrm{R}$ and weight vector $\mathrm{W}$ are calculated by the fuzzy synthesis operator and normalized to get the result set $\mathrm{S}$, as a result of comprehensive evaluation model made up of $(U, V, R, W)$.

The membership function woks as the basis of fuzzy comprehensive evaluation. Different evaluation methods have different range of each evaluation index value and the value of the evaluation index can be mapped to the interval $[0,1]$ through the membership function to gain a quantitative and intuitive result of the evaluation index. The membership function form must be selected according to the requirements of evaluation goals. The two common forms of membership functions are shown in Figure 5.

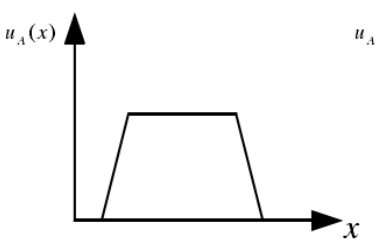

a)Trapezoidal form

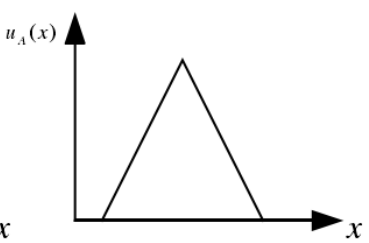

b)Triangle form
Figure 5. Diagram of the membership function

The core issue in comprehensive evaluation is to determine the weights in right way. When the evaluation system is more complex, it is difficult to directly give the weight of each evaluation index because of too many evaluation indicators and affecting each other; even though you do, the weight of each factor is very small to comply with the normalization, which is not conducive to analysis. Analytical Hierarchical Method (AHP) takes the advantage in determination of the weight of each evaluation index, so multi-level fuzzy comprehensive evaluation can matter 18 . The specific application of Analytical Hierarchical Method is seen in the Figure 6. 


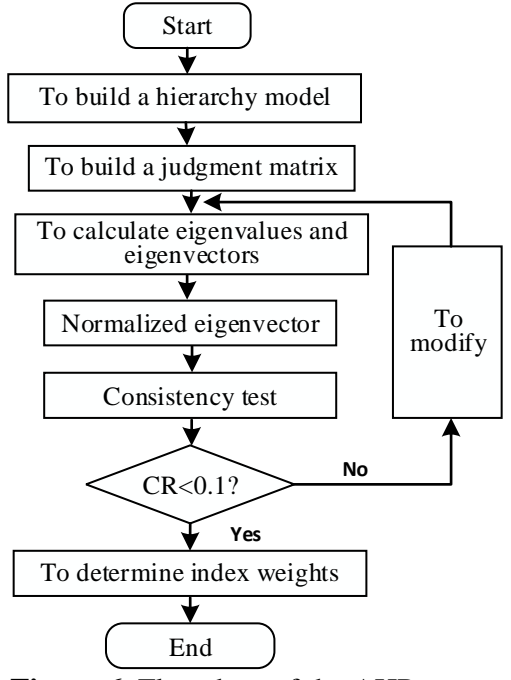

Figure 6. Flowchart of the AHP

\section{1) Structure judgment matrix}

First of all, it is necessary to analyze the questions and construct a hierarchical structure model. Then, according to the 9-level scale provided by F.L. Saaty scholars, the judgement matrix $\mathrm{A}$ is established by judging the importance of each level of evaluation indicators on the evaluation objectives. To compare the effect of $\mathrm{n}$ factors $\mathrm{X}=\left\{x_{1}, \ldots, x_{n}\right\}$ on the factor $\mathrm{Z}$, two factor $x_{i}$ and $x_{j}$ was taken and $a_{i j}$ is used to represent the relative importance of the influence of $x_{i}$ and $x_{j}$ on $\mathrm{Z}$ and a judgment matrix $\mathrm{A}=\left(a_{i j}\right)_{n \times n}$ is utilized to represent the comparison result, as shown in formula (1) and $\mathrm{A}$ serves as the judgment matrix between $\mathrm{Z}$ and $\mathrm{X}$.

$$
\mathrm{A}=\left[\begin{array}{cccc}
1 & a_{12} & \ldots & a_{1 m} \\
a_{21} & 1 & \ldots & a_{2 m} \\
\ldots & \ldots & \ldots & \ldots \\
a_{n 1} & a_{n 2} & \ldots & 1
\end{array}\right]
$$

Among them, the value of $a_{i j}$ is larger, if $a_{i j}>$ $0, a_{i i}=1$, which shows the greater the importance of $x_{i}$ to the evaluation target compared with $x_{j}$. The the impact of the importance ratio of $x_{i}$ and $x_{j}$ on $\mathrm{Z}$ is $a_{j i}=$ $1 / a_{i j} .9$ scales and their meanings are shown in the Table 5.

2) Calculation of eigenvalues and eigenvectors

The steps for hierarchical single sort: priority is given to get the max eigenvalue and eigenvector $\mathrm{W}$ of the judgment matrix $\mathrm{A}$ and normalize the $\mathrm{W}$ to obtain the sorting weight.

Table 5. Assignment Criteria of Elements in Judgment Matrix

\begin{tabular}{|c|c|}
\hline$a_{j i}$ & Definition \\
\hline 1 & $x_{i}$ and $x_{j}$ are equal in importance \\
\hline 2 & Between being equal and slight \\
\hline 3 & $\mathrm{x}_{\mathrm{i}}$ is slightly important than $\mathrm{x}_{\mathrm{j}}$ \\
\hline 4 & Between being slight and much \\
\hline 5 & $\mathrm{x}_{\mathrm{i}}$ is much important than $\mathrm{x}_{\mathrm{j}}$ \\
\hline 6 & Between being much and significant \\
\hline 7 & $\mathrm{x}_{\mathrm{i}}$ is significantly important than $\mathrm{x}_{\mathrm{j}}$ \\
\hline 8 & Between being significant and the most \\
\hline 9 & $\mathrm{x}_{\mathrm{i}}$ is the best important \\
\hline
\end{tabular}

3) Consistency examine of judgment matrix

In order to rank the importance of elements in the same problem, decision makers often suffer from the complexity of the problem and the subjective cause when looking at the problem, which results in discrepancies in the judgment results. To end this, it is necessary to adopt a consistent method of examination to determine whether the difference is allowed. The examination can be performed as follows:

a) Calculation of consistency index $\mathrm{CI}$

$$
\mathrm{CI}=\frac{\lambda_{\max }-n}{n-1}
$$

b) In order to measure the consistency of the matrix, a Random Consistency Index (RI) is a must. The RI values of the 1st to 9th judgment matrix are shown in Table 6.

Table 6. The random consistency index value RI of the judgment matrix

\begin{tabular}{|c|c|c|c|c|c|}
\hline $\mathrm{n}$ & 1 & 2 & 3 & 4 & 5 \\
\hline $\mathrm{RI}$ & 0 & 0 & 0.58 & 0.90 & 1.12 \\
\cline { 1 - 5 } $\mathrm{n}$ & 6 & 7 & 8 & 9 & \multicolumn{1}{|c}{} \\
\cline { 1 - 5 } $\mathrm{RI}$ & 1.12 & 1.24 & 1.32 & 1.41 & \multicolumn{2}{|c}{} \\
\cline { 1 - 3 } & \multicolumn{4}{|c|}{}
\end{tabular}

c) Calculation of consistency ratio

$$
\mathrm{CR}=\frac{C I}{R I}
$$

If $\mathrm{CR}<0.10$, it is considered that the importance sorting of the judgment matrix is in line with the requirements. If $\mathrm{CR} 0 \geq 10$, the judgment matrix needs to be modified until the consistency check of the total sorting meets the requirements.

4) Total sort of final evaluation index system

Integrating the weights in the single criteria can get the total sorting weights. Let $\mathrm{A}$ and $\mathrm{B}$ be the upper and lower levels respectively, where $\mathrm{A}=\left\{A_{1}, \ldots, A_{m}\right\}$, $\mathrm{B}=\left\{B_{1}, \ldots, B_{n}\right\}$ and $a_{1}, \ldots, a_{m}$, represents the total weight of each element in the A-layer. The single sort weights of the B-level elements in the criteria are $b_{1 j}, \ldots, b_{n j}$. Then, the total sorting weight of each factor of layer $\mathrm{B}, b_{1}, \ldots, b_{n}$ can be obtained by formula (4).

$$
b_{i}=\sum_{j=1}^{m} b_{i j} a_{j}, i=1, \ldots, n
$$

The accumulation of non-uniformity of the judgment matrix of each level may lead to inconsistency of the final total sorting weights, so the examination is implemented in total sorting of levels. The examination of the total sort random consistency can be calculated by equation (5):

$$
\mathrm{CR}=\frac{\sum_{j=1}^{m} C I(j) a_{j}}{\sum_{j=1}^{m} R I(j) a_{j}}
$$

Among: $\mathrm{CI}(\mathrm{j}),(\mathrm{j}=1, \ldots, \mathrm{m})$ refers to the consistency index with the corresponding judgment matrix $a \_j$ in the hierarchy;

$R I(j)$ refers to average random consistency index with the corresponding judgment matrix $a_{j}$ in the hierarchy;

If $\mathrm{CR}<0.10$, the level of total sorting ordering consistency is effective. If not, the weight CI values are obtained separately for the positive and negative matrices of different experts and the expert questionnaires whose CI values do not meet the requirements or the experts whose CI values is less 0.1 value are required to re-do questionnaires.

\section{5) Croup decision-making}

In order to overcome the subjective problem in determination of the weight of the analytic hierarchy 
process (AHP), the group decision-making of experts is a must and then aggregated to consider. The specific steps are shown in Figure 7:

\begin{tabular}{|c|c|c|}
\hline $\begin{array}{l}\text { Build } \\
\text { hierarchi }\end{array}$ & $\rightarrow \begin{array}{c}\text { Design } \\
\text { questionnaire }\end{array}$ & \\
\hline
\end{tabular}

Figure 7. Steps for group decision-making in weight calculation

\subsection{Fuzzy comprehensive evaluation procedure}

Through the analysis method of AHP-FCE, the evaluation index fails to be obtained directly while gaining it by analyzing the problem and then constructing a hierarchical model. Firstly, the problem is decomposed based on the AHP, then the middle layer is used as the evaluation index which is the alternative. The specific steps for completing a multilevel fuzzy comprehensive evaluation by the AHP-FCE method are as follows:

1) To figure out the evaluation target $U$ that refers to $\mathrm{U}=\left(u_{1}, u_{2}, \ldots, u_{n}\right)$ in which $\mathrm{n}$ means the number of indicators.

2) To build a multi-level evaluation index system. Firstly, the evaluation objectives are decomposed based on the problem analysis to form the alternatives and criteria, as a result of a multi-level evaluation model;

3) To determine the weight $\mathrm{W}$ of the evaluation. As for the fuzzy comprehensive evaluation, the weights of the evaluation are calculated by the AHP: $W=$ $\left(w_{1}, w_{2}, \ldots, w_{n}\right)$

4) To determine the set $\mathrm{V}$ of the level of the evaluation: the evaluation target is divided in level according to the different evaluation indicators; for example, the evaluation of the comfort of assembly operations are established in level: $\mathrm{V}=\left(v_{1}, v_{2}, \ldots, v_{m}\right)$;

5) To build a fuzzy relation matrix R. After construction of hierarchical fuzzy subsets is completed, a single-factor fuzzy relation matrix for each sub-indicator is gained:

$$
\mathrm{R}=\left[\begin{array}{cccc}
r_{11} & r_{12} & \ldots & r_{1 m} \\
r_{21} & r_{12} & \ldots & r_{2 m} \\
\ldots & \ldots & \ldots & \ldots \\
r_{n 1} & r_{n 2} & \ldots & r_{n m}
\end{array}\right]
$$

Among them, $r_{i j}$ refers to the membership of the evaluation target $u_{i}$ to the level fuzzy subset $v_{j}$.

6) To synthetize matrix $S$ of result of fuzzy comprehensive evaluation. Although the principle of maximum membership is used commonly but not applicable to all. The wrong use will lead to great deviations in the evaluation results and fail to reflect the truthfulness of the evaluation of the problems. Therefore, it is possible to use a method that can sort the membership level by weighted mean according to their sort for a lot of things. fuzzy operations on $\mathrm{W}$ and $\mathrm{R}$ are implemented by a synthesis algorithm, vector $S$, the final result of fuzzy comprehensive evaluation is obtained:

$$
\begin{array}{r}
\mathrm{S}=\mathrm{W} * \mathrm{R}=\left(w_{1}, w_{2}, \ldots, w_{n}\right) \\
*\left[\begin{array}{cccc}
r_{11} & r_{12} & \ldots & r_{1 m} \\
r_{21} & r_{12} & \ldots & r_{2 m} \\
\ldots & \ldots & \ldots & \ldots \\
r_{n 1} & r_{n 2} & \ldots & r_{n m}
\end{array}\right]
\end{array}
$$

$$
=\left(s_{1}, \wedge, s_{n}\right)
$$

Among them, $s_{i}$ refers to the membership of evaluated things as a whole to the fuzzy subset of $v_{j}$ grade.

The section is to figure out the overall goal of the ergonomic evaluation for simulation process of the virtual assembly and compare and analyze the existing evaluation methods in a systematical method as well as determine the AHP-FCE combination to model the comfort of assembly operations, in which the AHP is used to determine the weights of indicators. Then further study is made in the method of fuzzy comprehensive evaluation and the fuzzy comprehensive evaluation system of assembly operation comfort is achieved, which provides a solution to the ergonomic evaluation of virtual assembly.

\section{Conclusion}

This paper studied the virtual assembly operation and took the workers into consideration in the assembly planning. It's provide a more practical reference for virtual assembly design of product. A systematic analysis of the issues related to virtual assembly and ergonomics was conducted. A set of research ideas from virtual simulation to ergonomics evaluation was proposed. An evaluation index system for evaluation of ergonomic analysis methods for virtual assembly operations was constructed, and an assembly for virtual assembly was proposed. The work efficiency fuzzy comprehensive evaluation method, in the fuzzy comprehensive evaluation model, the weight is determined using a strong logic, practicality and systematic AHP. The establishment of the model is in line with the actual situation, which facilitates the promotion of simulation analysis before product design or operation tasks, early detection of whether the assembly process scheme meets the results of human factors and gives suggestions for improvement, and improves existing designs to promote humans-

(6) machine-environment integration. The comprehensive evaluation model has the advantages of simple calculation, good practical application value and application prospect, so it is able to provide theoretical support for academic research and applications in industry.

\section{References}

1. Chryssolouris G, Papakostas N, Mavrikios D. A perspective on manufacturing strategy: Produce more with less[J]. CIRP Journal of Manufacturing Science and Technology, 2008, 1(1):45-52.

2. Jin Yongming. Research on Maintainability Analysis and Evaluation Method of Ship: Shanghai Jiao Tong University, 2011.

3. Chryssolouris G, Mavrikios D, Fragos D, et al. A virtual reality-based experimentation environment for the verification of human -related factors in assembly processes $[\mathrm{J}]$. Robotics and ComputerIntegrated Manufacturing, 2000, 16(4): 267-276. 
4. Allen C, Karam K Z, Le Cam P, et al. Application of virtual reality devices to the quantitative assessment of manual assembly forces in a factory environment[C] Industrial Electronics, Control, and Instrumentation, 1995. Proceedings of the 1995 IEEE IECON 21st International Conference on. IEEE, 1995, 2: 1048-1053.

5. Mohamad D, Deros B M, Ismail A R, et al. RULA Analysis of Work-Related Disorder among Packaging Industry Worker Using Digital Human Modeling (DHM)[C] Advanced Engineering Forum. 2013, 10: 9-15.

6. Ming C L, Elmaraghy H A, Nee A Y C, et al. CAD model based virtual assembly simulation, planning and training[J]. CIRP Annals -Manufacturing Technology, 2013, 62(2):799-822.

7. Yao Y X, Xia P J, Liu J S, et al. A pragmatic system to support interactive assembly planning and training in an immersive virtual environment (I VAPTS $[\mathrm{J}]$. The International Journal of Advanced Manufacturing Technology, 2006, 30(9-10): 959967

8. Han Hu. Research on Human-Computer Interaction Scene Control Technology for Virtual Assembly of Aircraft[A]. Proceedings of 2017 International Conference on Advances in Materials, Machinery, Electrical Engineering (AMMEE 2017) [C]. 2017:4.

9. ZHINAN QIN. Research on Immersive Virtual Assembly Based on Virtual Reality Technology[A]. Proceedings of The 2nd Asia-Pacific Management and Engineering Conference (APME 2016) [C]. 2016:6.

10. Alzuheri A, Luong L, Xing K. Ergonomics design measures in manual assembly work[C]// Second International Conference on Engineering Systems Management and ITS Applications. IEEE, 2010:1-6.

11. Botti L, Mora C, Regattieri A. Integrating ergonomics and lean manufacturing principles in a hybrid assembly line[J]. Computers \& Industrial Engineering, 2017, 14 (3) :350-355.

12. Rossi d, Bertoloni E, Fenaroli M, et al. A multi criteria ergonomic and performance methodology for evaluating alternatives in "manuable" material handling $[\mathrm{J}]$. International Journal of Industrial Ergonomics, 2013, 43(4): 314-327.

13. Yang Q, Wu D L, Zhu H M, et al. Assembly operation process planning by mapping a virtual assembly simulation to real operation[J]. Computers in Industry, 2013, 64(7):869-879.

14. Zhao J. Study on the Application of the Virtual Technology in the Mechanical Assembly Process[C]// International Conference on Mechanical Engineering and Intelligent Systems. 2015.

15. Usman S, Zhu H T, Haq M U. Design Improvement of Assembly Workplace through Ergonomic Simulation and Analysis Using DELMIA[J]. International Journal of Engineering Research in Africa, 2016, 21:238-246.

16. Botti L, Mora C, Regattieri A. Application of a mathematical model for ergonomics in lean
manufacturing[J]. Data Brief, 2017, 14(C):360-365.

17. Zhao Shuping, Liu Hongyang, Sun Gang Et al. Spacecraft assembly safety evaluation model based on fuzzy comprehensive evaluation [J]. Spacecraft Environment Engineering, 2014.,23:218-226

18. Ye Zhen. Study and Application of Fuzzy Comprehensive Evaluation Basedon AHP [D]. Guangzhou: South China University of Technology Guangzhou, 2010. 